\title{
County Median Family Income Is an Independent Prognostic Factor for Stage IV Anaplastic Thyroid Cancer
}

\author{
MU LI $^{1}$, SOPHI GU ${ }^{2}$, RUI MAO ${ }^{3}$, YING NING ${ }^{1}$, NITIN TRIVEDI ${ }^{4}$, \\ AHMAD SIDDIQUI ${ }^{5}$, PENGYANG $\mathrm{LI}^{1}$ and LIHONG HUO ${ }^{4}$ \\ ${ }^{1}$ Department of Internal Medicine, St Vincent Hospital, Worcester, MA, U.S.A.; \\ ${ }^{2}$ M.D. Program, Johns Hopkins University School of Medicine, Baltimore, MA, U.S.A.; \\ ${ }^{3}$ Department of Thoracic Surgery, Shanghai Pulmonary Hospital, \\ Tongji University School of Medicine, Shanghai, P.R. China; \\ ${ }^{4}$ Division of Endocrinology, Department of Internal Medicine, St Vincent Hospital, Worcester, MA, U.S.A.; \\ ${ }^{5}$ Division of Hematology/Oncology, Department of Internal Medicine, St Vincent Hospital, Worcester, MA, U.S.A.
}

\begin{abstract}
Background/Aim: Advanced anaplastic thyroid cancer (ATC) is a rare, but highly aggressive malignancy, and its prognostic factors need to be further explored. We examined socioeconomic factors' predictive effect for survival performance in stage IV ATC patients. Materials and Methods: Using the Surveillance, Epidemiology, and End Results database, we collected 1,048 cases with stage IV anaplastic thyroid cancer (ATC) from 2004 to 2015. Demographic, clinical, and socioeconomic factors were evaluated using univariate and multivariate analyses. Results: Median family income showed a significant effect on overall survival (OS) and cancer-specific survival (CSS) in univariate analysis. Median family income level was found to be an independent prognostic factor for OS after multivariate adjustment Multivariate analysis for CSS showed similar results. Conclusion: Family income level is an independent prognostic factor for stage IV ATC.
\end{abstract}

Anaplastic thyroid cancer (ATC) is rare, but is one of the most lethal neoplasms in humans (1). Arising in the thyroid follicular epithelium, ATC is composed of undifferentiated cells that lack classic features of the thyroid gland and is, thus, also known as undifferentiated thyroid cancer (2). While it comprises of just $2 \%$ of all thyroid cancers, it accounts for up to $50 \%$ of mortality associated with thyroid cancer (3). Death often follows only a few months following diagnosis - median

Correspondence to: Lihong Huo, Division of Endocrinology, Department of Internal Medicine, St Vincent Hospital, 123 Summer Street, Worcester, MA 01608, U.S.A. Tel: +1 5083635630, e-mail: lihong.huo66@gmail.com

Key Words: Anaplastic thyroid cancer, socioeconomic factors, county level median family income, prognostic factor. survival is 5 months (4), and less than $20 \%$ of patients survive for more than one year (5). This grim prognosis of ACT is likely due to the combination of occult symptoms, difficult diagnosis, and poor response to therapy $(6,7)$.

Considering the exceptionally aggressive nature of ATC, it is essential to identify its prognostic factors. Previous studies have confirmed that clinical factors including tumor size, presence of acute symptoms, extent of disease, leukocytosis, and treatment type impact survival (8-14). Recent studies have suggested that socioeconomic factors (SEF); such as marital status, insurance type, regional prosperity and educational attainment may also be important to consider as part of the prognosis of cancer disease (1520). Studies on the importance of SEF in thyroid cancer, however, have so far mainly addressed well differentiated thyroid cancers rather than ATC (21-24).

In this study, we examined the impact of several SEFs, as well as traditional clinical factors on the survival of patients with stage IV ATC. Our aim was to further understand the role of common SEFs in the prognosis of advanced ATC and find more evidence for improving the quality of public health studies and associated policies.

\section{Materials and Methods}

Data source. All data was extracted from the 2017 Surveillance, Epidemiology, and the End Results (SEER) database of the National Cancer Institute using the SEER*Stat 8.3.5 software.

Since 1973, the SEER program has published epidemiological information on cancer statistics in the United States, covering approximately $28 \%$ of the population (25). This version of the database was based on November 2017 submission and includes treatment information regarding radiation and chemotherapy (https://seer.cancer.gov).

Criteria for inclusion and exclusion. We extracted data on stage IV anaplastic thyroid cancer cases from January 2004 through 
December 2015 (staging standard: American Joint Committee on Cancer staging manual 6th edition, [AJCC 6]). Cases were identified via the primary site label, "C73.9-Thyroid Gland." The histology type was defined by the International Classification of Diseases for the Oncology code: ICD-O-8020/3 to ICD-O-8022/3. Patients with an unknown marital status, 0 days of survival, and incomplete survival data were excluded.

Variables involved. Clinically relevant data including sex, age $(<65$ or $\geq 65$ years), race (white or non-white), cancer stage (IVA, IVB, IVC and IV NOS [non-specific], AJCC 6), and treatment for thyroid cancer (including surgery, radiation, and chemotherapy) were involved.

Socioeconomic data regarding marital status and insurance type were also included. Single, widowed, separated, and divorced patients were categorized as unmarried. Insurance status included Medicaid, insurance other than Medicaid, unknown status, and uninsured. County-level socioeconomic factors were analyzed using updated county attributes (2012-2016 data). County-level high school education rate, unemployment rate, severity of language barriers, and median family income were categorized as Q1 (low performance, lower quartile), Q2 (medium performance, 50th percentile), or Q3 (high performance, upper quartile).

Statistical analysis. The primary outcomes were overall survival (OS) and cancer specific survival (CSS). Death from any reason was defined as an event in OS, while CSS event was defined as death due to ATC. Mean and standard deviation values were used to present continuous variables, and percentages were used to present categorical variables. We used the Kaplan-Meier method and $\log$ rank tests for the univariate analysis. Demographic, clinical factors and statistically significant SEFs were further evaluated with multivariate Cox proportional hazard models. Two-sided $p$-values $<0.05$ were considered significant. All data was analyzed using SPSS 20.0 (Statistics Package for Social Science, Chicago, IL, USA).

\section{Results}

Patient characteristics. Our study included 1048 Stage IV ATC cases from 2004 to 2015. Information regarding demographics, clinical factors, and SEFs is listed in Table I. The mean age was $70.23 \pm 12.33$ years. Patients were predominantly female $(61.74 \%)$, white $(79.10 \%)$ and $\geq 65$ years old $(66.70 \%)$. The proportion of patients with stage IVC $(\mathrm{n}=469,44.75 \%)$ was nearly equivalent to the combined proportion of patients with IVA and IVB (10.69\% and $35.21 \%$, respectively). Nearly half of the patients received surgery, radiation, and/or chemotherapy $(44.66 \%, 55.96 \%$, and $41.60 \%$, respectively). More than half of the patients $(56.58 \%)$ were married at the time of diagnosis. Approximately $50 \%$ of patients had insurance other than Medicaid.

Overall survival. Among clinical factors, univariate analysis (Table II) showed that patients under $65(p<0.001)$ and white patients $(p=0.041)$ had better OS. Higher cancer stages were associated with a worse OS $(p<0.001)$. Any type of treatment (surgery, chemotherapy, or radiation) seemed to favor improved OS $(p<0.001)$. In the multivariate analysis, all
Table I. Baseline demographic, clinical and socioeconomic features. SEER 2004-2015 ( $n=1048)$.

\begin{tabular}{lc}
\hline Characteristic & No. of cases $(\%)$ \\
\hline Total & 1048 \\
Age & \\
$<65$ & $349(33 \%)$ \\
$\geq 65$ & $699(67 \%)$ \\
Gender & \\
Female & $647(62 \%)$ \\
Male & $401(38 \%)$ \\
Race & \\
White & $829(79 \%)$ \\
Non-white & $219(21 \%)$ \\
AJCC Stage & \\
IVA & $112(11 \%)$ \\
IVB & $369(35 \%)$ \\
IVC & $469(45 \%)$ \\
IVNOS & $98(9 \%)$ \\
Primary surgery & \\
No surgery & $574(55 \%)$ \\
Surgery to thyroid & $468(45 \%)$ \\
Unknown & $6(1 \%)$ \\
Chemotherapy & \\
No known Tx & $612(58 \%)$ \\
Confirmed Tx & $436(42 \%)$ \\
Radiation simple & \\
No known Tx & \\
Confirmed Tx & $472(45 \%)$ \\
Marital status & $576(55 \%)$ \\
Unmarried & \\
Married & $455(43 \%)$ \\
Insurance & $593(57 \%)$ \\
Medicaid & \\
Insured, other than medicaid & $126(12 \%)$ \\
Uninsured & $526(50 \%)$ \\
Unknown status & \\
\hline & \\
\hline
\end{tabular}

Tx, Treatment.

factors mentioned above except for race remained significant (Table II). White patients did not show higher survival after adjustment using the Cox regression analysis $(p=0.39)$.

In the univariate analysis (Table II), adverse prognostic factors included being unmarried $(p<0.001)$ and living in counties with a lower average level of high school education $(p<0.001)$ or with a higher unemployment rate $(p=0.024)$. Patients living in counties with a lower quartile median family income were found to have a worse OS (Figure 1; 3 year survival in Q1, Q2 and Q3 groups were 0\%, 9.35\%, and $7.87 \%$, respectively; $p=0.016$ ). Insurance type and countylevel of language isolation did not affect OS ( $p=0.594$ and 0.146 , respectively). In the multivariate analysis, median family income remained as an independent prognostic factor (Q1 vs. Q2: hazard ratio (HR), 0.75; 95\% confidence interval (CI), 0.60-0.94; $p=0.013$; Q1 vs. Q3: HR, 0.70; 95\% CI, $0.54-0.91 ; p=0.008)$. 
Table II. Univariate and multivariate survival analyses for stage IV undifferentiated thyroid cancer patients' overall survival (OS) factors. SEER 2004-2015 (n=1048).

\begin{tabular}{|c|c|c|c|c|c|c|}
\hline \multirow[t]{2}{*}{ Variables } & \multirow[b]{2}{*}{ 3-year OS } & \multicolumn{2}{|c|}{ Univariate analysis } & \multicolumn{3}{|c|}{ Multivariate analysis } \\
\hline & & Log rank $\chi^{2}$ & $p$-Value & HR & $95 \% \mathrm{CI}$ & $p$-Value \\
\hline Gender & & 1.31 & 0.252 & & & \\
\hline Female & $7.59 \%$ & & & Reference & & \\
\hline Male & $8.03 \%$ & & & 1.01 & $0.87-1.16$ & 0.913 \\
\hline Age & & 32.00 & $<0.001$ & & & \\
\hline$<65$ & $11.74 \%$ & & & Reference & & \\
\hline$\geq 65$ & $5.92 \%$ & & & 1.34 & $1.16-1.55$ & $<0.001$ \\
\hline Race & & 4.17 & 0.041 & & & \\
\hline White & $8.56 \%$ & & & Reference & & \\
\hline Non-white & $4.68 \%$ & & & 0.93 & $0.79-1.09$ & 0.388 \\
\hline AJCC Stage & & 134.57 & $<0.001$ & & & \\
\hline IV A & $25.08 \%$ & & & Reference & & \\
\hline IV B & $9.98 \%$ & & & 1.45 & $1.14-1.84$ & $<0.001$ \\
\hline IV C & $1.50 \%$ & & & 2.35 & $1.84-2.99$ & $<0.001$ \\
\hline IV NOS & $6.80 \%$ & & & 1.44 & $1.07-1.94$ & 0.017 \\
\hline Primary surgery & & 146.12 & $<0.001$ & & & \\
\hline No surgery & $1.98 \%$ & & & Reference & & \\
\hline Surgery to thyroid & $14.80 \%$ & & & 0.53 & $0.46-0.61$ & $<0.001$ \\
\hline Unknown & $0.00 \%$ & & & 0.84 & $0.37-1.92$ & 0.683 \\
\hline Chemotherapy & & 109.72 & $<0.001$ & & & \\
\hline No known Tx & $4.91 \%$ & & & Reference & & \\
\hline Confirmed Tx & $11.78 \%$ & & & 0.68 & $0.58-0.79$ & $<0.001$ \\
\hline Radiation simple & & 158.79 & $<0.001$ & & & \\
\hline No known Tx & $3.84 \%$ & & & Reference & & \\
\hline Confirmed Tx & $10.93 \%$ & & & 0.58 & $0.50-0.67$ & $<0.001$ \\
\hline Marital status & & 12.36 & $<0.001$ & & & \\
\hline Unmarried & $6.30 \%$ & & & Reference & & \\
\hline Married & $9.00 \%$ & & & 0.91 & $0.79-1.04$ & 0.170 \\
\hline Insurance & & 1.90 & 0.594 & & & \\
\hline Medicaid & $7.06 \%$ & & & N/A & N/A & N/A \\
\hline Insured, other than medicaid & $7.17 \%$ & & & N/A & N/A & N/A \\
\hline Uninsured & $13.97 \%$ & & & N/A & N/A & N/A \\
\hline Unknown status & $8.65 \%$ & & & N/A & N/A & N/A \\
\hline High school education $\S$ & & 13.22 & $<0.001$ & & & \\
\hline Q1 & $3.32 \%$ & & & Reference & & \\
\hline Q2 & $10.34 \%$ & & & 0.93 & $0.75-1.15$ & 0.494 \\
\hline Q3 & $6.85 \%$ & & & 0.98 & $0.74-1.29$ & 0.870 \\
\hline Unemployment & & 7.49 & 0.024 & & & \\
\hline Q1 & $6.96 \%$ & & & Reference & & \\
\hline Q2 & $8.99 \%$ & & & 1.05 & $0.85-1.31$ & 0.650 \\
\hline Q3 & $7.22 \%$ & & & 1.08 & $0.83-1.40$ & 0.557 \\
\hline Language isolation & & 3.84 & 0.146 & & & \\
\hline Q1 & $5.53 \%$ & & & N/A & N/A & N/A \\
\hline Q2 & $9.33 \%$ & & & N/A & N/A & N/A \\
\hline Q3 & $7.38 \%$ & & & N/A & N/A & N/A \\
\hline Median family income & & 8.32 & 0.016 & & & \\
\hline Q1 & $0.00 \%$ & & & Reference & & \\
\hline Q2 & $9.35 \%$ & & & 0.75 & $0.60-0.94$ & 0.013 \\
\hline Q3 & $7.87 \%$ & & & 0.70 & $0.54-0.91$ & 0.008 \\
\hline
\end{tabular}

Tx, Treatment. Socioeconomic factors which did not show statistical significance were not included in the multivariate analysis. ${ }^{\S}$ High school education rate, unemployment rate, language isolation rate and median family income level were categorized in three levels according to their performance percentile. Q1 represented the worst 25\% among all counties, Q2 represented the middle 50\% and Q3 represented the best $25 \%$.

Cancer-specific survival. Among clinical factors, race, stage, surgery, chemotherapy and radiation therapy showed a significant effect on CSS in univariate analysis (Table III, $p=0.010, p<0.001, p<0.001, p<0.001, p<0.001$, respectively).
In the multivariate analysis, stage and treatments remained significant predictors of CSS (Table III).

In the univariate analysis, patients from counties with a lower quartile median family income had worse 3 -year CCS 
Table III. Univariate and multivariate survival analysis for stage IV undifferentiated thyroid cancer patient's cancer specific survival (CSS) factors. SEER 2004-2015 $(n=1048)$.

\begin{tabular}{|c|c|c|c|c|c|c|}
\hline \multirow[t]{2}{*}{ Variables } & \multirow[b]{2}{*}{ 3-year CSS } & \multicolumn{2}{|c|}{ Univariate analysis } & \multicolumn{3}{|c|}{ Multivariate analysis } \\
\hline & & Log rank $\chi^{2}$ & $p$-Value & HR & $95 \% \mathrm{CI}$ & $p$-Value \\
\hline Gender & & 2.81 & 0.294 & & & \\
\hline Female & $16.29 \%$ & & & Reference & & \\
\hline Male & $16.99 \%$ & & & 0.94 & $0.80-1.12$ & 0.505 \\
\hline Age & & 2.85 & 0.092 & & & \\
\hline$<65$ & $15.41 \%$ & & & Reference & & \\
\hline$>=65$ & $18.03 \%$ & & & 1.07 & $0.91-1.26$ & 0.415 \\
\hline Race & & 6.704 & 0.010 & & & \\
\hline White & $18.30 \%$ & & & Reference & & \\
\hline Non-white & $10.41 \%$ & & & 1.00 & $0.83-1.20$ & 0.982 \\
\hline AJCC stage & & 141.21 & $<0.001$ & & & \\
\hline IV A & $46.46 \%$ & & & Reference & & \\
\hline IV B & $20.50 \%$ & & & 1.69 & $1.25-2.30$ & 0.001 \\
\hline IV C & $41.56 \%$ & & & 3.08 & $2.26-4.19$ & $<0.001$ \\
\hline IV NOS & $15.86 \%$ & & & 1.75 & $1.20-2.54$ & 0.003 \\
\hline Primary surgery & & 114.89 & $<0.001$ & & & \\
\hline No surgery & $5.15 \%$ & & & Reference & & \\
\hline Surgery to thyroid & $27.86 \%$ & & & 0.52 & $0.44-0.62$ & $<0.001$ \\
\hline Unknown & $0.00 \%$ & & & 0.88 & $0.36-2.17$ & 0.783 \\
\hline Chemotherapy & & 56.52 & $<0.001$ & & & \\
\hline No known Tx & $14.70 \%$ & & & Reference & & \\
\hline Confirmed Tx & $19.61 \%$ & & & 0.71 & $0.60-0.86$ & $<0.001$ \\
\hline Radiation simple & & 105.26 & $<0.001$ & & & \\
\hline No known Tx & $10.36 \%$ & & & Reference & & \\
\hline Confirmed Tx & $20.97 \%$ & & & 0.58 & 0.49-0.69 & $<0.001$ \\
\hline Marital status & & 14.49 & $<0.001$ & & & \\
\hline Unmarried & $14.37 \%$ & & & Reference & & \\
\hline Married & $18.47 \%$ & & & 0.83 & $0.71-0.98$ & 0.027 \\
\hline Insurance & & 3.14 & 0.371 & & & \\
\hline Medicaid & $0.00 \%$ & & & N/A & N/A & N/A \\
\hline Insured, other than medicaid & $15.37 \%$ & & & N/A & N/A & N/A \\
\hline Uninsured & $0.00 \%$ & & & N/A & N/A & N/A \\
\hline Unknown status & $17.92 \%$ & & & N/A & N/A & N/A \\
\hline High school education & & 10.18 & 0.006 & & & \\
\hline Q1 & $10.02 \%$ & & & Reference & & \\
\hline Q2 & $20.89 \%$ & & & 0.95 & $0.77-1.18$ & 0.642 \\
\hline Q3 & $13.45 \%$ & & & 0.99 & $0.76-1.29$ & 0.932 \\
\hline Unemployment & & 4.72 & 0.094 & & & \\
\hline Q1 & $16.88 \%$ & & & N/A & N/A & N/A \\
\hline Q2 & $18.37 \%$ & & & N/A & N/A & N/A \\
\hline Q3 & $14.96 \%$ & & & N/A & N/A & N/A \\
\hline Language Isolation & & 2.61 & 0.271 & & & \\
\hline Q1 & $15.91 \%$ & & & N/A & N/A & N/A \\
\hline Q2 & $18.01 \%$ & & & N/A & N/A & N/A \\
\hline Q3 & $14.66 \%$ & & & N/A & N/A & N/A \\
\hline Median Family Income & & 6.51 & 0.039 & & & \\
\hline Q1 & $0.00 \%$ & & & Reference & & \\
\hline Q2 & $18.11 \%$ & & & 0.74 & $0.57-0.96$ & 0.021 \\
\hline Q3 & $17.79 \%$ & & & 0.73 & $0.54-0.99$ & 0.041 \\
\hline
\end{tabular}

compared to the other groups (Figure 2; 3-year survival rates in Q1, Q2 and Q3 groups were 0\%, 18.11\%, and $17.79 \%$, respectively; $p=0.039)$. Patients who were married, resided in counties with higher levels of education and with a higher median family income exhibited a better CSS $(p<0.001$, $p=0.006$, and $p=0.039$, respectively). In the multivariate analysis, following an adjustment for demographic and clinical factors, marital status (Table III, unmarried $v s$. married: HR, $0.83,95 \%$ CI $0.71-0.98, p=0.027)$ and the county median family income (Q1 vs. Q2: HR, 0.74; $95 \%$ CI, 0.57-0.96; $p=0.021$; Q1 vs. Q3: HR, 0.73; 95\% CI, $0.54-$ $0.99 ; p=0.041)$ remained independent predictors of CSS. 


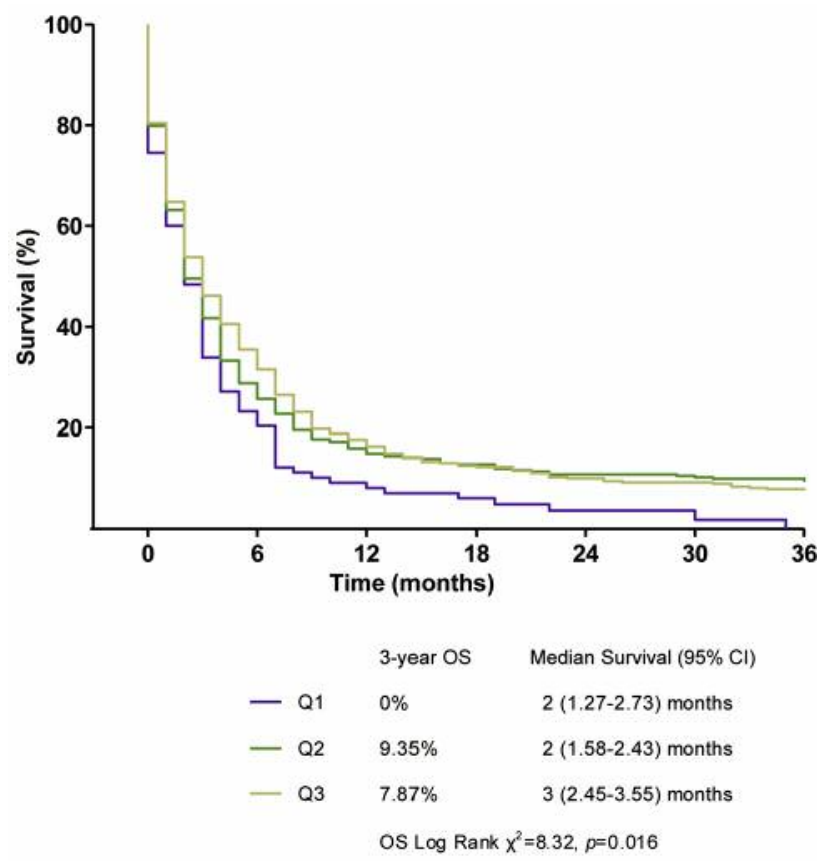

Figure 1. Overall survival curves in patients with stage IV UTC.

\section{Discussion}

Given that ATC is one of the most aggressive human malignancies, it is vital to identify relevant prognostic factors, both clinical and non-clinical $(26,27)$. In recent decades, many studies about socioeconomic factors' effect on disease and medical care have been conducted (28-30). Considering these facts, our study analyzed the impact of common SEFs on advanced ATC prognosis, and demonstrated that regional family income level is independently associated with OS and CSS in stage IV ATC.

After adjusting for sex, age, race, stage, and treatment type, we found that living in regions with a lower median family income relates with a worse prognosis of stage IV ATC patients. Many studies have shown that socioeconomic disparities negatively impact outcomes in cancer patients. In a large study of 229,195 breast cancer cases, county-level median family income was an independent prognostic factor for both overall survival and cancer-specific survival (31). A study of Chinese patients with thyroid cancer found that the per capita disposable income significantly affected the health-related quality of life (32). Similar findings have also been well-described in other common cancer types, including lung cancer, colorectal cancer, and prostate cancer (33-35). In the United States, Kaposi sarcoma as well as cancers of the larynx, cervix, penis, and liver showed the largest

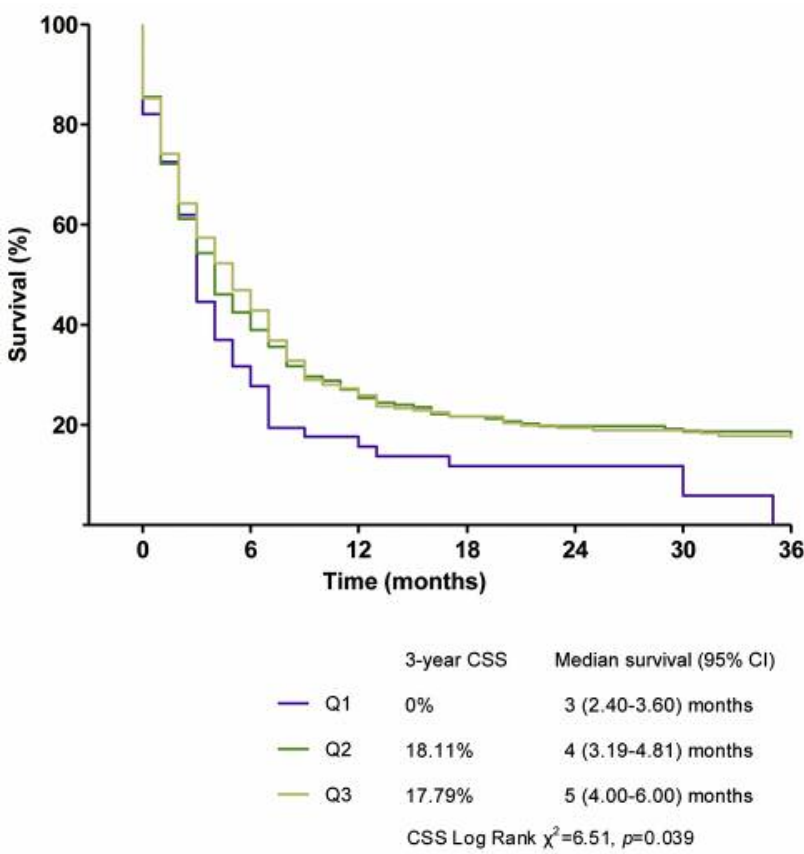

Figure 2. Cancer-specific survival curves in patients with stage IV ATC.

survival disparities were associated with the socioeconomic status of the patients (36). Regarding ATC, however, only few studies have previously noted the impact of poverty. In a study of 719 patients with ATC, Roche et al. found that poorer patients had a worse prognosis (35). Our study corroborated this finding.

There may be several explanations for the negative impact of poverty on survival in ATC. Firstly, financial difficulties may reflect lower levels of social support, which are important for determining health outcomes. Rice et al. studied the relationship between social network and cancer, and highlighted the importance of social network in providing economic resources, social involvement and tailored interventions (37). Secondly, the psychological impact of poverty may negatively impact health outcomes, as poorer individuals may experience decreased levels of autonomy and self-awareness (38). Thirdly, accessing more advanced treatment modalities is likely an obstacle for residents of low-income areas (39), while one study has shown that cancer survival rates increase with advances in treatment options (40). Fourthly, it has been proposed that poverty may be associated with a delayed diagnosis of cancer (36), but the evidence for this is conflicting. Singer et al have found poverty to be a significant prognostic factor even after adjusting for cancer stage (36), indicating that poverty affects the prognosis independent of delays in cancer 
diagnosis. A study on lung cancer, however, has found that the impact of income on survival becomes insignificant after adjustment for clinical factors (33). Thus, further research delving into the relationship between income and cancer survival is necessary.

Marital status is a well-known SE prognostic factor in common cancer disease $(17,31,41)$. In our study, patients who were unmarried showed lower OS and CSS in the univariate analysis. This effect was confirmed with the multivariate analysis of CSS. The other SEFs that we investigated, including the insurance type, the level of education, and the language isolation rate, did not show a significant impact on survival in stage IV ATC. Previous studies examining the influence of these SEFs on cancer survival have revealed controversial results. Niu et al. found that cancer patients on Medicaid had a worse prognosis than those on private insurance (42). Another study on childhood cancer has shown similar survival rates between patients on Medicaid and patients on private insurance (43). The level of education did not seem to impact breast cancer-specific survival in a large sample study (44). In another study, however, Williams et al. found that patients from counties with high rates of college education were more likely to accept radical cystectomy and have better OS (45). In a study on childhood acute myeloid leukemia, immigration-related features, including regional language isolation rate, were not independent prognostic factors (46). These results also highlight the need for further exploration of the effect of insurance type, level of education, and language isolation rate on ATC.

Our current study has several limitations. The SEER database provided us with the opportunity to carry out a relatively large sample study of ATC, but the database had inherent limitations. Firstly, since the database did not provide longitudinal data on the income status, we could not take into consideration the effect of changes in the income status on the patients' outcome. For instance, the median family income of a county may vary with time or patients may move to a county with a different median family income post-diagnosis. Secondly, the database provided county-level rather than individual-level information regarding the income, employment, and the level of education. Although countylevel and individual-level variables are likely associated with one another, we are also very interested in the impact of personal socioeconomic status. Thirdly, SEER database only provided limited clinical information, excluding patient's comorbidities, chemotherapy plan/duration and radiation therapy details. Fourthly, DTC stage was defined using the AJCC 6 standard, however, using the latest AJCC 8 staging system would possibly be more reliable.

In conclusion, regional socioeconomic factors could affect stage IV ATC patients' survival performance. Patients from counties with the lowest median family income had a worse survival performance. Further studies with a larger sample size are necessary to further understand the relationship between regional economic status and ATC prognosis, and hopefully shift more health resources to be distributed to regions with a lower economic development level to improve ATC survival.

\section{Conflicts of Interest}

The Authors of this article have no conflicts of interest to declare.

\section{Authors' Contributions}

$\mathrm{Mu} \mathrm{Li}$ and Lihong Huo did most of the study design and manuscript preparation. $\mathrm{Mu} \mathrm{Li}$ and Rui Mao did most of the data analysis. Ying Ning and Pengyang Li participated in validating the data analysis. Sophie Gu, Ahmad Siddiqui and Nitin Trivedi contributed towards editing the manuscript. All authors contributed in the manuscript revision.

\section{Acknowledgements}

This study was not supported by any funding.

\section{References}

1 Zhang X, Liu L, Deng X, Li D, Cai H, Ma Y, Jia C, Wu B, Fan $\mathrm{Y}$ and Lv Z: Microrna 483-3p targets pard3 to potentiate tgfbeta1-induced cell migration, invasion, and epithelialmesenchymal transition in anaplastic thyroid cancer cells. Oncogene, 2018. PMID: 30171257, DOI: 10.1038/s41388-0180447-1.

2 Thompson LD: Undifferentiated thyroid carcinoma. Ear Nose Throat J 92(10/11): 500, 2013. PMID: 24170460.

3 Molinaro E, Romei C, Biagini A, Sabini E, Agate L, Mazzeo S, Materazzi G, Sellari-Franceschini S, Ribechini A, Torregrossa L, Basolo F, Vitti P and Elisei R: Anaplastic thyroid carcinoma: From clinicopathology to genetics and advanced therapies. Nat Rev Endocrinol 13(11): 644-660, 2017. PMID: 28707679, DOI: 10.1038/nrendo.2017.76.

4 Smallridge RC and Copland JA: Anaplastic thyroid carcinoma: Pathogenesis and emerging therapies. Clin Oncol (R Coll Radiol) 22(6): 486-497, 2010. PMID: 20418080, DOI: 10.1016/j.clon.2010.03.013.

5 Kebebew E, Greenspan FS, Clark OH, Woeber KA and McMillan A: Anaplastic thyroid carcinoma. Treatment outcome and prognostic factors. Cancer 103(7): 1330-1335, 2005. PMID: 15739211, DOI: 10.1002/cncr.20936.

6 Deeken-Draisey A, Yang GY, Gao J and Alexie BA: Anaplastic thyroid carcinoma: An epidemiologic, histologic, immunohistochemical and molecular single institution study. Hum Pathol, 2018. PMID: 30075157, DOI: 10.1016/ j.humpath.2018.07.027.

7 Raue F and Frank-Raue K: Thyroid cancer: Risk-stratified management and individualized therapy. Clin Cancer Res 22(20): 5012-5021, 2016. PMID: 27742787, DOI: 10.1158/ 1078-0432.CCR-16-0484.

8 Haymart MR, Banerjee M, Yin H, Worden F and Griggs JJ: Marginal treatment benefit in anaplastic thyroid cancer. Cancer 119(17): 3133-3139, 2013. PMID: 23839797, DOI: 10.1002/ cncr.28187. 
9 Kihara M, Miyauchi A, Yamauchi A and Yokomise $\mathrm{H}$ : Prognostic factors of anaplastic thyroid carcinoma. Surg Today 34(5): 394-398, 2004. PMID: 15108075, DOI: 10.1007/s00595003-2737-6.

10 Kim TY, Kim KW, Jung TS, Kim JM, Kim SW, Chung KW, Kim EY, Gong G, Oh YL, Cho SY, Yi KH, Kim WB, Park DJ, Chung JH, Cho BY and Shong YK: Prognostic factors for korean patients with anaplastic thyroid carcinoma. Head Neck 29(8): 765-772, 2007. PMID: 17274052, DOI: 10.1002/hed.20578.

11 Mohebati A, Dilorenzo M, Palmer F, Patel SG, Pfister D, Lee N, Tuttle RM, Shaha AR, Shah JP and Ganly I: Anaplastic thyroid carcinoma: A 25-year single-institution experience. Ann Surg Oncol 21(5): 1665-1670, 2014. PMID: 24554064, DOI: 10.1245/s10434-014-3545-5.

12 Akaishi J, Sugino K, Kitagawa W, Nagahama M, Kameyama K, Shimizu K, Ito K and Ito K: Prognostic factors and treatment outcomes of 100 cases of anaplastic thyroid carcinoma. Thyroid 21(11): 1183-1189, 2011. PMID: 21936674, DOI: $10.1089 /$ thy.2010.0332.

13 Sugitani I, Miyauchi A, Sugino K, Okamoto T, Yoshida A and Suzuki S: Prognostic factors and treatment outcomes for anaplastic thyroid carcinoma: Atc research consortium of japan cohort study of 677 patients. World J Surg 36(6): 1247-1254, 2012. PMID: 22311136, DOI: 10.1007/s00268-012-1437-z.

14 Zivaljevic V, Tausanovic K, Paunovic I, Diklic A, Kalezic N, Zoric G, Sabljak V, Vekic B, Zivic R, Marinkovic J and Sipetic $\mathrm{S}$ : Age as a prognostic factor in anaplastic thyroid cancer. Int $\mathrm{J}$ Endocrinol 2014: 240513, 2014. PMID: 25024703, DOI: $10.1155 / 2014 / 240513$.

$15 \mathrm{Wu} \mathrm{Y,} \mathrm{Ai} \mathrm{Z} \mathrm{and} \mathrm{Xu} \mathrm{G:} \mathrm{Marital} \mathrm{status} \mathrm{and} \mathrm{survival} \mathrm{in} \mathrm{patients}$ with non-small cell lung cancer: An analysis of 70006 patients in the seer database. Oncotarget 8(61): 103518-103534, 2017. PMID: 29262581, DOI: 10.18632/oncotarget.21568.

16 Wang L, Wilson SE, Stewart DB and Hollenbeak CS: Marital status and colon cancer outcomes in us surveillance, epidemiology and end results registries: Does marriage affect cancer survival by gender and stage? Cancer Epidemiol 35(5): 417-422, 2011. PMID: 21466984, DOI: 10.1016/ j.canep.2011.02.004.

17 Tyson MD, Andrews PE, Etzioni DA, Ferrigni RG, Humphreys MR, Swanson SK and Castle EK: Marital status and prostate cancer outcomes. Can J Urol 20(2): 6702-6706, 2013. PMID: 23587510 .

18 Adekolujo OS, Tadisina S, Koduru U, Gernand J, Smith SJ and Kakarala RR: Impact of marital status on tumor stage at diagnosis and on survival in male breast cancer. Am J Mens Health 11(4): 1190-1199, 2017. PMID: 27694551, DOI: $10.1177 / 1557988316669044$.

19 Saad AM, Abushouk AI, Al-Husseini MJ, Salahia S, Alrefai A, Afifi AM and Abdel-Daim MM: Characteristics, survival and incidence rates and trends of primary cardiac malignancies in the united states. Cardiovasc Pathol 33: 27-31, 2018. PMID: 29414429, DOI: 10.1016/j.carpath.2017.12.001.

20 Truong B, Green AL, Friedrich P, Ribeiro KB and RodriguezGalindo C: Ethnic, racial, and socioeconomic disparities in retinoblastoma. JAMA Pediatr 169(12): 1096-1104, 2015. PMID: 26436436, DOI: 10.1001/jamapediatrics.2015.2360.

21 Lubitz CC, Kong CY, McMahon PM, Daniels GH, Chen Y, Economopoulos KP, Gazelle GS and Weinstein MC: Annual financial impact of well-differentiated thyroid cancer care in the united states. Cancer 120(9): 1345-1352, 2014. PMID: 24481684, DOI: $10.1002 /$ cncr.28562.

22 Shi RL, Qu N, Lu ZW, Liao T, Gao Y and Ji QH: The impact of marital status at diagnosis on cancer survival in patients with differentiated thyroid cancer. Cancer Med 5(8): 2145-2154, 2016. PMID: 27264532, DOI: 10.1002/cam4.778.

23 Shi RL, Qu N, Liao T, Wei WJ, Wang YL and Ji QH: The trend of age-group effect on prognosis in differentiated thyroid cancer. Sci Rep 6: 27086, 2016. PMID: 27272218, DOI: 10.1038/ srep27086.

24 Zhang D, Tang J, Kong D, Cui Q, Wang K, Gong Y and Wu G: Impact of gender and age on the prognosis of differentiated thyroid carcinoma: A retrospective analysis based on seer. Horm Cancer, 2018. PMID: 30014218, DOI: 10.1007/s12672-0180340-y.

25 National Cancer Institute: Surveillance, epidemiology, and end results. Https://seer.Cancer.Gov/data-software/documentation/ seerstat/nov2017/.

26 Hsu KT, Yu XM, Audhya AW, Jaume JC, Lloyd RV, Miyamoto S, Prolla TA and Chen H: Novel approaches in anaplastic thyroid cancer therapy. Oncologist 19(11): 1148-1155, 2014. PMID: 25260367, DOI: 10.1634/theoncologist.2014-0182.

27 Keutgen XM, Sadowski SM and Kebebew E: Management of anaplastic thyroid cancer. Gland Surg 4(1): 44-51, 2015. PMID: 25713779, DOI: 10.3978/j.issn.2227-684X.2014.12.02.

28 DeRouen MC, Schupp CW, Yang J, Koo J, Hertz A, ShariffMarco S, Cockburn M, Nelson DO, Ingles SA, Cheng I, John EM and Gomez SL: Impact of individual and neighborhood factors on socioeconomic disparities in localized and advanced prostate cancer risk. Cancer Causes Control, 2018. PMID: 30136012, DOI: 10.1007/s10552-018-1071-7.

29 Correa-Burrows P, Rodriguez Y, Blanco E, Gahagan S and Burrows R: Increased adiposity as a potential risk factor for lower academic performance: A cross-sectional study in chilean adolescents from low-to-middle socioeconomic background. Nutrients 10(9): 2018. PMID: 30134573, DOI: 10.3390/ nu10091133.

30 Niessen LW, Mohan D, Akuoku JK, Mirelman AJ, Ahmed S, Koehlmoos TP, Trujillo A, Khan J and Peters DH: Tackling socioeconomic inequalities and non-communicable diseases in low-income and middle-income countries under the sustainable development agenda. Lancet 391(10134): 2036-2046, 2018. PMID: 29627160, DOI: 10.1016/S0140-6736(18)30482-3.

31 Gong Y, Zhang J, Ji P, Ling H, Hu X and Shao ZM: Incidence proportions and prognosis of breast cancer patients with bone metastases at initial diagnosis. Cancer Med 7(8): 4156-4169, 2018. PMID: 29984914, DOI: 10.1002/cam4.1668.

32 Wang T, Jiang M, Ren Y, Liu Q, Zhao G, Cao C and Wang H: Health-related quality of life of community thyroid cancer survivors in hangzhou, china. Thyroid 28(8): 1013-1023, 2018. PMID: 29808769, DOI: 10.1089/thy.2017.0213.

33 Mehta AJ, Stock S, Gray SW, Nerenz DR, Ayanian JZ and Keating NL: Factors contributing to disparities in mortality among patients with non-small-cell lung cancer. Cancer Med, 2018. PMID: 30264921, DOI: 10.1002/cam4.1796.

34 Attard TM and Lawson CE: Comparison of the demographic characteristics of pediatric and adult colorectal cancer patients: A national inpatient sample based analysis. World J Pediatr, 2018. PMID: 30259389, DOI: 10.1007/s12519-018-0187-x. 
35 Weiner AB, Matulewicz RS, Tosoian JJ, Feinglass JM and Schaeffer EM: The effect of socioeconomic status, race, and insurance type on newly diagnosed metastatic prostate cancer in the united states (2004-2013). Urol Oncol 36(3): 91 e91-91 e96, 2018. PMID: 29153624, DOI: 10.1016/j.urolonc.2017.10.023.

36 Singer S, Bartels M, Briest S, Einenkel J, Niederwieser D, Papsdorf K, Stolzenburg JU, Kunstler S, Taubenheim S and Krauss O: Socio-economic disparities in long-term cancer survival-10 year follow-up with individual patient data. Support Care Cancer 25(5): 1391-1399, 2017. PMID: 27942934, DOI: 10.1007/s00520-016-3528-0.

37 Rice LJ and Halbert CH: Social networks across common cancer types: The evidence, gaps, and areas of potential impact. Adv Cancer Res 133: 95-128, 2017. PMID: 28052823, DOI: 10.1016/bs.acr.2016.09.002.

38 Marmot M: Health in an unequal world: Social circumstances, biology and disease. Clin Med (Lond) 6(6): 559-572, 2006. PMID: 17228555.

39 Victora CG, Vaughan JP, Barros FC, Silva AC and Tomasi E: Explaining trends in inequities: Evidence from brazilian child health studies. Lancet 356(9235): 1093-1098, 2000. PMID: 11009159, DOI: 10.1016/S0140-6736(00)02741-0.

40 Lyratzopoulos G, Barbiere JM, Rachet B, Baum M, Thompson MR and Coleman MP: Changes over time in socioeconomic inequalities in breast and rectal cancer survival in england and wales during a 32-year period (1973-2004): The potential role of health care. Ann Oncol 22(7): 1661-1666, 2011. PMID: 21199888, DOI: 10.1093/annonc/mdq647.

41 Varlotto JM, McKie K, Voland RP, Flickinger JC, DeCamp MM, Maddox D, Rava PS, Fitzgerald TJ, Walsh W, Oliveira P, Rassaei $\mathrm{N}$, Baima $\mathrm{J}$ and $\mathrm{Uy} \mathrm{K}$ : The role of race and economic characteristics in the presentation and survival of patients with surgically resected non-small cell lung cancer. Front Oncol 8: 146, 2018. PMID: 29868470, DOI: 10.3389/fonc.2018.00146.
42 Niu X, Roche LM, Pawlish KS and Henry KA: Cancer survival disparities by health insurance status. Cancer Med 2(3): 403-411, 2013. PMID: 23930216, DOI: 10.1002/cam4.84.

43 Lee JM, Wang X, Ojha RP and Johnson KJ: The effect of health insurance on childhood cancer survival in the united states. Cancer 123(24): 4878-4885, 2017. PMID: 28891067, DOI: 10.1002/cncr.30925

44 Agarwal S, Ying J, Boucher KM and Agarwal JP: The association between socioeconomic factors and breast cancerspecific survival varies by race. PLoS One 12(12): e0187018, 2017. PMID: 29211739, DOI: 10.1371/journal.pone.0187018.

45 Williams SB, Huo J, Kosarek CD, Chamie K, Rogers SO, Jr., Williams MA, Giordano SH, Kim SP and Kamat AM: Population-based assessment of racial/ethnic differences in utilization of radical cystectomy for patients diagnosed with bladder cancer. Cancer Causes Control 28(7): 755-766, 2017. PMID: 28477210, DOI: 10.1007/s10552-017-0902-2.

46 Knoble NB, Alderfer MA and Hossain MJ: Socioeconomic status (ses) and childhood acute myeloid leukemia (aml) mortality risk: Analysis of seer data. Cancer Epidemiol 44: 101-108, 2016. PMID: 27543948, DOI: 10.1016/ j.canep.2016. 07.007.

Received December 27, 2018

Revised January 20, 2019

Accepted January 21, 2019 